\title{
The Money Neutrality Proposition: Is Boosting Money Supply A Solution To US Economic Problems?
}

\author{
Jean Emmanuel Fonkoua, Strayer University, USA
}

\begin{abstract}
This paper unfastens the new classical structural model and broadens the reduced form output equation to investigate the money neutrality proposition in the United States. The hypothesis that any predictable monetary policy has no influence on output is extended by the inclusion of foreign exchange rationing to the supply side of the economy as cointegrated with money supply. The final prediction error determines the proper lag length that is used by the dynamic analysis to examine the causality relationship between imports, foreign price, foreign income, and output. The vector autoregressive is used to determine the exogeneity property of foreign exchange and output; it also helps extract the anticipated and unanticipated components of foreign exchange and money series. Empirical evidence provides considerable support for short run cyclical movements in the output of highly industrialized countries in affecting the real output in the United States. Indeed, any policy response in raising output should take into account the well-being of other developed countries. Predicted or not, an increase in the level of growth of other advanced countries does not leads to offsetting expectation and results in raising the economic growth. Empirical test presents no evidence that boosting the money supply leads to an increase in the level of growth. The result also refutes the view that the United States can quickly recover through a monetary policy aimed at depreciating the dollar and stands against the idea that devaluation tends to expand domestic output in industrialized countries. Incompatible with the economic logic is the lack of support of the apparent reality of output determination in industrialized countries open economy models.
\end{abstract}

Keywords: Cointegration; Final Prediction Error; Money Neutrality; Money Supply; Unit Root; Vector Autoregressive; Vector Error Correction

\section{INTRODUCTION}

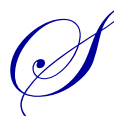

tudies on the movement of money and output, an issue of interest among economists, have attempted to analyze the extent to which movements in money supply causes fluctuations in real output in open economies. Even though the perception seems to differ on ground of hypotheses, all the theories lead to the determination of the role of money on growth. Researchers have used a straightforward application of the Barrotype two-stage framework; therefore, eliminating the influence of open economy variables. Studies that take into account variables of open economies include them in an arbitrary fashion. Previous studies also fail to include economic characteristics that are emphasized in the theoretical framework of open economy models. The neglect of these issues could bias the estimate of the interaction between money and output in industrialized countries with open market economies.

\section{METHODOLOGICAL ANALYSIS}

The money neutrality position postulates the ineffectiveness of monetary instrument on growth. Therefore, policy makers should not attempt to stabilize the economy through the use of monetary policy because money does not affect output. Hence, money does not matter for growth and boosting money supply has no effect on output. In 
this study, the interaction between money and output is extended by the introduction of open economy variables as cointegrated with money on the supply side of the economy.

\section{The Quantity Money Theory}

The determination of the simple quantity money theory employs the identity MV = PY

$\mathrm{M}$ represents the money, $\mathrm{V}$ stands for the velocity of the money, $\mathrm{P}$ is the price, and $\mathrm{Y}$ denotes the output. The economy theory assumes the velocity of money to be identity thus reducing the equation to $M=P Y$ so $Y=M / P$.

Assuming $\log \mathrm{Y}=\mathrm{y}, \log \mathrm{M}=\mathrm{m}$, and $\log \mathrm{P}=\mathrm{p}$, the above equality is reformulated as $\mathrm{y}=\mathrm{m}-\mathrm{p}$. Fixing output in its natural rate zero out y and establish the identity $\mathrm{m}=\mathrm{p}$. Therefore, monetary policy has no effect on output; only real factors and aggregate fluctuations in the economy determine the optimal level of output. The neutrality state of the money thus tackles the issues of output being unaffected by money and any response of the systematic monetary policy resulting in price effect because money and price adjust one on one.

\section{The Economy Supply}

The economy consists of many individuals producing goods using their own labor and these goods are sold in a market. The money earned from sales is used to purchase other goods. Each producer possesses its own production function which is the individual supply function and expresses through the equality $\mathrm{Q}_{i}=\mathrm{L}_{i}$ where $\mathrm{Q}_{i}$ and $\mathrm{L}_{i}$ are respectively the individual production function and the producer supply function of the good i. Economic theory states that the individual consumption equals its income adjusted by the price level $\mathrm{c}_{i}=\mathrm{p}_{i} \mathrm{q}_{i} / \mathrm{P}$ where $\mathrm{c}_{i}$ stands for the individual consumption of $\operatorname{good} \mathrm{i}, \mathrm{p}_{i}$ is the price of good $\mathrm{i}, \mathrm{q}_{i}$ denotes the quantity of good $\mathrm{i}$, and $\mathrm{P}$ is the general price level. The utility is function of consumption and labor $\mathrm{U}=\mathrm{c}_{i}-\left(\mathrm{Li}^{\gamma} / \gamma\right)$ with $\gamma>1$

$\mathrm{U}$ is the utility and $\gamma$ determines the level of work. The individual maximizes its utility by choosing consumption and labor and each individual faces a maximization problem that gives rise to the optimal level of work. The optimal level of labor supply is determined by the equality $\mathrm{L}_{i}=\mathrm{Q}_{i}=\left(\mathrm{P}_{i} / \mathrm{P}\right)^{1 /(1-\gamma)}$. Introduction of logarithms to the above equation results in $\log \left(\mathrm{L}_{i}\right)=\log \left(\mathrm{Q}_{i}\right)=1 /(\gamma-1) \log \left(\mathrm{P}_{i}-\mathrm{P}\right)$. Assuming $\log \left(\mathrm{L}_{i}\right)=1_{i}, \log \left(\mathrm{Q}_{i}\right)=\mathrm{q}_{i}$, the above equality becomes $1_{i}=\mathrm{q}_{i}=(1 /(\gamma-1))\left(\mathrm{p}_{i}-\mathrm{p}\right)$ where $\left(\mathrm{p}_{i}-\mathrm{p}\right)$ stands for the relative price of good i. Because $1_{i}$ increases as $\left(\mathrm{p}_{i}-\mathrm{p}\right)$ rises, the production of an individual is increasing in relative price of the product $\mathrm{i}$. In spite of linking production, labor, and relative price, the above individual supply accounts for (a) the rise in labor as the real wage increases under the assumption that the individual works only; (b) the rise in price of the producer own product as the real product price increases which in turn boosts the level of output under the assumption that the supplier is a producer only; and (c) the increase in sales as the individual purchases more consumption goods and prices get higher; this process is done through inter temporal substitution from periods in which the real product price is low to those in which it is high.

\section{Inclusion of Imperfect Information}

The signaling function of the market does not work perfectly which causes producers to oversupply in response to unanticipated increase in the aggregate price level. Important information regarding the price level is imperfect when the price of the supplier product is high relative to the aggregate price level driving the producer to increase the supply of its goods. The formulation of anticipated and unanticipated movements of the aggregate output and thus price necessitates an adjustment of the supply function to account for imperfect information. The price of the supplier own product increases as the aggregate price level rises. The producer only knows his own price and may mistakenly interpret the rise in price as an increase in the real product price whereas the price increase is part of the general price rise. The unexpected shift in supply fools the producer into believing that the random relative demand movement is in its favor. The unanticipated change in supply convinces the producer that it exists an unexpected relative increase in the market of its good, and hence a rise in its relative price. Therefore, the 
movement in the money supply is subdivided into two elements: the expected and the unexpected components. The individual supply function is thus determined using the expectation of the price level conditional to the information set available to the producer and the supplier own product price. The steps used in the development of the model are (a) the decomposition of the money supply into anticipated and unanticipated components; (b) the empirical support that it is only the random movement in money that raises the level of output; and (c) the expected components of money supply results in the rise of the aggregate price level.

Under imperfect information, the aggregate price level is unknown and the individual supply is modified to account for expectation, so $\mathrm{q}_{i}=(1 /(\gamma-1))\left(\mathrm{p}_{t}^{i}-\mathrm{E}_{t}\left[\mathrm{p}_{t} / \mathrm{I}_{t}^{i}\right]\right)$. The supplier forms a priori distribution of the product price $\mathrm{p}_{t}^{i}$ different from the aggregate price level $\mathrm{p}_{t}$ in order to decide how much to produce. An expectation of the general price level is derived before the supplier own product price is observed. The first set of information may be available not only to the producer, but to everyone raising the issue of economic market shocks. The second set of information may come from the observation of the supplier own product price. Based on the two forms of information set, the aggregate price level and the price of good i satisfy the relationship $\mathrm{p}_{t}^{i}=\mathrm{p}_{t}+\mathrm{z}_{t}^{i}$. The price of the producer $\mathrm{i}$ at time $\mathrm{t}\left(\mathrm{p}_{t}^{i}\right)$ equals the aggregate price $\left(\mathrm{p}_{t}\right)$ and a market specific shock $\left(\mathrm{z}_{t}^{i}\right)$. It is assumed that the shocks are independently and identically distributed with mean zero; therefore, the expectation of the product price of the supplier $\mathrm{i}$ at time $\mathrm{t}$ equals the expectation of the aggregate product price $\mathrm{E}\left(\mathrm{p}_{t}^{i}\right)=\mathrm{E}\left(\mathrm{p}_{t}\right)$. Decomposition of the composite disturbance observed by the supplier is done through an empirical evaluation that employs the statistical formula $\delta_{(a+b)}^{2}=\delta_{a}^{2}+\delta_{b}^{2}+\operatorname{cov}_{(a+b)}$. With the assumption of independently and identically distributed errors with mean zero and known variance, the above equality becomes $\delta_{(a+b)}^{2}=\delta_{a}^{2}+\delta_{b}^{2}$, this helps shape the shock faced by the supplier as $\delta_{p_{t}^{i}}^{2}=\delta_{p_{t}}^{2}+\delta_{z_{t}^{i}}^{2}$. Under imperfect information, the shock faced by the producer $\delta_{p_{t}^{i}}^{2}$ is the sum of the shock associated with the aggregate price level $\delta_{p_{t}}^{2}$ and the market specific shock $\delta_{z_{t}^{i}}^{2}$.

Estimation of the aggregate price level is the weighted average of prior expectation and realization, so $\mathrm{E}_{t}[\mathrm{p}$ $\left.\left.{ }_{t} / \mathrm{I}_{t}^{i}\right]\right)=(1-\theta) \mathrm{E}_{t}\left[\mathrm{p}_{t} / \mathrm{I}_{t}\right]+\theta \mathrm{p}_{t}^{i}$. The weight with which prior expectations enter the equation depends on the variance of the shocks $\theta=\delta_{p}^{2} /\left(\delta_{p}^{2}+\delta_{z}^{2}\right)$. Thus $\left.\mathrm{E}_{t}\left[\mathrm{p}_{t} / \mathrm{I}_{t}^{i}\right]\right)=\left(1-\left(\delta_{p}^{2} /\left(\delta_{p}^{2}+\delta_{z}^{2}\right)\right) \mathrm{E}_{t}\left[\mathrm{p}_{t} / \mathrm{I}_{t}\right]\right)+\left(\delta_{p}^{2} /\left(\delta_{p}^{2}+\delta_{z}^{2}\right)\right) \mathrm{p}_{t}^{i}$. If the market shocks sum up to zero, the weighted average of the shock is one $\theta=\delta_{p}^{2} /\left(\delta_{p}^{2}+\delta_{z}^{2}\right)=\delta_{p}^{2} / \delta_{p}^{2}$. Substitution of $\theta$ by its value in $\left.\mathrm{E}_{t}\left[\mathrm{p}_{t} / \mathrm{I}_{t}^{i}\right]\right)$ determines the aggregate price level $\mathrm{E}_{t}\left[\mathrm{p}_{t} / \mathrm{I}_{t}^{i}\right]=\mathrm{p}_{t}^{i}$. The supplier product price is identical to the expectation of the aggregate price given the information set available. Substitution of the aggregate price level into the individual supply function results in $\mathrm{q}^{i}=\left(\left(\left(1 /(\gamma-1) \mathrm{p}_{t}^{i}\right)-(1-\theta)\right) \mathrm{E}_{t}\left[\mathrm{p}_{t} / \mathrm{I}_{t}\right]+\theta \mathrm{p}_{t}^{i}\right)$, whose development is $\mathrm{q}^{i}=1 /(\gamma-1) \mathrm{p}_{t}^{i}-\left(1 /(\gamma-1)(1-\theta) \mathrm{E}_{t}\left[\mathrm{p}_{t} / \mathrm{I}_{t}\right]-\left(1 /(\gamma-1) \theta \mathrm{p}_{t}^{i}\right.\right.$, and factor under $1 /(\gamma-1)$ yields the individual supply function under imperfect information $\mathrm{q}^{i}=\left((1 /(\gamma-1)(1-\theta))\left(\mathrm{p}_{t}^{i}-\mathrm{E}_{t}\left[\mathrm{p}_{t} / \mathrm{I} t\right]\right)\right.$. Aggregation over all individual suppliers depends on the relative variance of the market shocks $\theta=\delta_{p}^{2} /\left(\delta_{p}^{2}+\delta_{z}^{2}\right)$. Subsequently, the weight with which prior expectations enter the equation $(1-\theta)=1-\left(\delta_{p}^{2} /\left(\delta_{p}^{2}+\delta_{z}^{2}\right)\right.$ helps determine the slope of the equation as $\mathrm{b}=(1 /(\gamma-1))\left(\delta_{z}^{2} /\left(\delta_{p}^{2}+\delta_{z}^{2}\right)\right)$.

The producer is likely to be less confused by unsystematic movements in the money supply thinking that its market experiences a positive relative demand shift. The total of the random increase demand shift in all markets for 
individual suppliers is obtained by aggregation of all producers that believe to an unanticipated relative increase in the demand for their product due to a positive unexpected shift in the supply of their goods. Totaling for all individual suppliers yields the total output through aggregation of $\mathrm{q}^{i}$ as $\mathrm{Y}=\mathrm{b}\left(\mathrm{p}_{t}^{i}-\mathrm{E}_{t}\left[\mathrm{p}_{t} / \mathrm{I}_{t}\right]\right)$.

$\mathrm{Y}$ represents the aggregate income, $\mathrm{P}$ denotes the price, $\mathrm{E}$ stands for the expectation, $\mathrm{I}$ is the information set available, and $i$ and $t$ are respectively producer and time indexes. Under imperfect information, the neutrality state of the money is summarized as the effect of an unanticipated price rise which becomes bigger as the variance of the market specific shock $\delta_{z}^{2}$ increases relative to the variance of the aggregate price level $\delta_{p}^{2}$. The tendency of firms to over supply is due to an unexpected increase in the price level; this is interpreted as the rise in the real product price because most of the variability is due to sector specific shock rather than general price rise. The neutrality state of the money is derived from the economy wide shocks that sums up to zero and the average price across all goods which is a weighted factor related to the number and the market of goods.

\section{Equilibrium Conditions}

The expression for domestic output is done by setting the aggregate demand equals the aggregate supply as $\mathrm{Y}_{t}^{s}=\mathrm{Y}_{t}^{d}$, therefore $\mathrm{m}_{t}-\mathrm{p}_{t}=\mathrm{b}\left(\mathrm{p}_{t}^{i}-\mathrm{E}_{t}\left[\mathrm{p}_{t} / \mathrm{I}_{t}\right]\right)$ whose development $\mathrm{bp}_{t}+\mathrm{p}_{t}=\mathrm{m}_{t}+\mathrm{bE}_{t}\left[\mathrm{p}_{t} / \mathrm{I}_{t}\right]$ and factor under $\mathrm{p}_{t}$ yields $\mathrm{p}_{t}(1+\mathrm{b})=\mathrm{m}_{t}+\mathrm{bE}_{t}\left[\mathrm{p}_{t} / \mathrm{I}_{t}\right]$. Given the information set available to the producer, the expectation at time $\mathrm{t}$ of the aggregate price equals the aggregate money, so $\mathrm{E}_{t}\left[\mathrm{p}_{t} / \mathrm{I}_{t}\right]=\mathrm{E}_{t}\left[\mathrm{~m}_{t} / \mathrm{I}_{t}\right]$, thus $\mathrm{p}_{t}(1+\mathrm{b})=\mathrm{m}_{t}+\mathrm{bE}_{t}\left[\mathrm{~m}_{t} / \mathrm{I}_{t}\right]$ and $\mathrm{p}_{t}$ $=(1 /(1+\mathrm{b}))\left(\mathrm{m}_{t}+\mathrm{bE}_{t}\left[\mathrm{~m}_{t} / \mathrm{I}_{t}\right]\right)$. This sets up the relation between money and price. Solving for aggregate output $\mathrm{Y}_{t}$ $=\mathrm{m}_{t}-\mathrm{p}_{t}$ yields $\mathrm{Y}_{t}=\mathrm{m}_{t}-\left((1 /(1+\mathrm{b}))\left(\mathrm{m}_{t}+\mathrm{bE}_{t}\left[\mathrm{~m}_{t} / \mathrm{I}_{t}\right]\right)\right)$, arranging results in $\mathrm{Y}=\mathrm{m}-(1 /(1+\mathrm{b})) \mathrm{m}-((\mathrm{b} /(1+\mathrm{b}))(\mathrm{E}[\mathrm{m} / \mathrm{I}]))$, and factor under $1 /(1+\mathrm{b})$ yields $\mathrm{Y}_{t}=(1-(1 /(1+\mathrm{b}))) \mathrm{m}_{t}-\left((\mathrm{b} /(1+\mathrm{b}))\left(\mathrm{E}_{t}\left[\mathrm{~m}_{t} / \mathrm{I}_{t}\right]\right)\right)$. In fact, $1-(1 /(1+\mathrm{b}))=\mathrm{b} /(1+\mathrm{b})$, so the aggregate output is $\mathrm{Y}_{t}=(\mathrm{b} /(1+\mathrm{b}))\left(\mathrm{m}_{t}-\mathrm{E}_{t}\left[\mathrm{~m}_{t} / \mathrm{I}_{t}\right]\right)$.

The unexpected component of the money supply is given by the difference between real and anticipated change in the money. The economic logic within the framework provided by this equation is that the systematic change in the monetary policy is expected by individuals before the policy is implemented resulting in zero effect of the anticipated movement of the monetary policy in boosting the level of economic growth. Variations in output are the result of errors and thus cannot be optimal and persistent movement in aggregates variables cannot be explained. The model presents no dynamic in its basic form and the lag structure enters the system via expectation formed on the basis of information available. The formal argument underlying the money policy ineffectiveness is that the nonrandom component of the monetary policy exerts no influence on output and only the random part affects the level of growth because any policy response that is predictable results in offsetting expectations.

\section{PREVIOUS LITERATURE AND DATA CONSIDERATIONS}

Using a two-steps procedure, Barro (1978) finds that only unsystematic changes in the monetary policy affect output in the United States. Despite the significance of the money policy ineffectiveness in applying the Barro-type equation in countries with open market economies, critics have been made to the application of the reduced form output in open economies. Nwaobi (2004) emphasizes the negative consequences of relevant variables exclusion when applying the Barro-type model in economies with open markets; the author acknowledges difficulties to establish the form in which open variables should appear in the model. Wallace and CabreraCastellanos (2006) also contend that the economic variables used in the money neutrality suffer from endogeneity bias. Another way to look at the Barro-type equation consists of including relevant factors that matter for growth in open economies. In this respect, a particular focus is shifted to studies of Attfield and Duck (1983), Edwards (1983), and Sheehey (1984); they add in an ad hoc fashion to the equation, variables considered relevant to open economies. 
Secondary data of the United States Department of Commerce (Bureau of Economic Analysis) and the Lexis Nexus database (1960-2010) are essential components of the groundwork for the empirical testing of the theoretical analysis. The economic reality reveals that variations in the economic activity of other advanced countries affect the output growth of industrialized economies. In this regard, it is noticeable that the real output function includes an index of the growth rate of high level business partners of the United States. Exchanges between the United States and other industrialized countries have been strengthened over the years as perceived by the structure of the economy. Indeed, the secular movements of the value of the dollar affect output growth of the United States. It is therefore noticeable that the real output function includes the domestic exchange rate for the dollar against the aggregate of industrialized countries to estimate the influence of output fluctuation on business cycle of the United States. The functional form of economic models generally specified output in real terms on the assumption that price elasticity on nominal output is unity. In this respect, the foreign real income and the real output use an index conversion procedure to convert the series to 1995 base year. The unavailability of an index of exchange rate of industrialized countries for the years 1960 to 1977 leads to update the missing foreign price years. As it is known, there is a scant theoretical direction for the selection of broad money M2; it is motivated by its use in most similar studies. The import and money variables are expressed in billions of dollars. Prior research has also demonstrated the need to avoid potential bias and eliminate the presence of outliers through the use of the percentage change in the values of the variables. The logarithm value of all variables are thus used to squeeze together larger values and stretch out smaller values.

\section{FOREIGN EXCHANGE LED GROWTH THEORY}

Inline with critics of the money policy ineffectiveness, it is worthwhile examining the form in which foreign exchange variables enter the model of open market economies. This research looks at the way to introduce and posit open economy variables in the growth model in order to orient the policy variables. According to Nwaobi (2004), foreign exchange rationing is consistent with the specification of aggregate supply since it operates through the supply side and thus could explicitly establish a model setting conform to the structural type of open economies.

\section{Theoretical Analysis}

Jaleel and Kwan (1991) use a quantitative assessment to examine the link between export and output. The exclusion of other relevant variables that matter for growth and the absence of the dynamic structure in the process lead Kwan and Kwok (1995) to reformulate the model. The causality relation between open economy variables and real output is derived from the export led growth hypothesis. The empirical consideration in the conditional model is that foreign exchange variables are weakly exogenous. The causal relationship between foreign exchanges and output is posited in the form $\mathrm{Yr}_{t}=\mathrm{f}\left(\left\{\mathrm{Yr}_{t-j}\right\}_{j=1}^{k},\left\{\mathrm{~V}_{t-j}\right\}_{i=0}^{m}, \mathrm{v}_{t}, \alpha\right)$ where $\mathrm{Yr}$ denotes the growth rate of real output and $\mathrm{V}$ is the growth rate of foreign exchange variables, $\mathrm{v}$ stands for all the other variables that enter the equation, $\alpha$ represents the vector of coefficients distributed independently and identically with mean zero and finite variance, and $t$ denotes an index of time. The included lag length $\mathrm{i}, \mathrm{m}, \mathrm{j}, \mathrm{k}$, illustrates the idea of the model carrying an autoregressive specification. Differentiation of the original variables is considered as the statistical logic of modern financial time series examination; therefore, the foreign exchange led growth is reformulated as $\Delta \operatorname{Yr}_{t}=\mathrm{f}\left(\left\{\Delta \operatorname{Yr}_{t-j}\right.\right.$ \}$\left._{j=1}^{k},\left\{\Delta \mathrm{V}_{t-j}\right\}_{i=0}^{m}, \mathrm{v}_{t}, \alpha\right)$, with the operator $\Delta$ representing the difference in two consecutive time periods. The causality property of $\Delta \mathrm{V}$ determines the validity of the foreign exchange led growth hypothesis since the marginal model accounts for past realizations of the real output. Dealing with the foreign exchange led growth theory requires the determination of the value that minimizes the final prediction error through the formula ${ }^{*}=[(\mathrm{S}+\mathrm{N}) /(\mathrm{S}-$ $\mathrm{N})] /(\mathrm{SSR} / \mathrm{S})$. While fixing $\mathrm{m}$ conditional to $\mathrm{k} . \mathrm{k}^{*}$ denotes the final prediction error of $\mathrm{k}, \mathrm{S}$ represents the sample size, $\mathrm{N}$ stands for the number of parameters, and SSR is the sum of squares residuals.

\section{Rank Prediction, Lag Length, and Causality Relationship}

The rank prediction of the theoretical model represents the constraints imposed in the movements of foreign exchanges and output by the financial system in a long term horizon in the presence of short run digression 
from the estimated equilibrium. Among numerous techniques, the model selection criterion is selected and the results are given below:

Table 1- Rank prediction using the model selection criteria

\begin{tabular}{|l|c|l|l|}
\hline \multicolumn{1}{|c|}{ Variables } & Rank & \multicolumn{1}{|c|}{ Selected Model } & \multicolumn{1}{|c|}{ Criteria } \\
\hline \multirow{2}{*}{ Output and import } & $\mathrm{r}=1$ & Quadratic intercept and trend & Akaike Information \\
\cline { 2 - 4 } & $\mathrm{r}=0$ & Linear intercept and no trend & Schwarz Information \\
\hline \multirow{2}{*}{ Output and foreign price } & $\mathrm{r}=1$ & Linear intercept and trend & Akaike Information \\
\cline { 2 - 4 } & $\mathrm{r}=0$ & No intercept and no trend & Schwarz Information \\
\hline \multirow{2}{*}{ Output and foreign income } & $\mathrm{r}=1$ & Quadratic intercept and trend & Akaike Information \\
\cline { 2 - 4 } & $\mathrm{r}=1$ & Linear intercept and trend & Schwarz Information \\
\hline
\end{tabular}

Using the model selection criteria, there is a clear conflict between the test results based on the Schwarz and the Akaike information criteria. The Akaike information determines the rank prediction of the theoretical association between foreign exchanges and output to be one. Turning to Schwartz information, the rank prediction of imports, foreign price, and output on one side and foreign income and output on the other side seem inconclusive with the cointegration relation between two series. Consistent with Greene (2003) these data provide support to the superiority of the Akaike over the Schwartz information when dealing with small sample properties.

A two-steps procedure helps determine the proper lag length that is used throughout this study. The process consists of setting a value conditional to $\mathrm{k}$ in the causality equation as a way to look for the value that minimizes $\mathrm{k}$. The final prediction error of $\mathrm{k}$ is reached when $\mathrm{k}$ attains its minimum. Results are given in the table below:

Table 2 - Final prediction error

\begin{tabular}{|l|c|c|c|}
\hline \multicolumn{1}{|c|}{ Variables } & Lag & FPE (k) & FPE (k, i) \\
\hline Output and import & 0 & & 4536.04 \\
\cline { 2 - 4 } & 1 & 3124.69 & 1377.24 \\
\cline { 2 - 4 } & 2 & 837.08 & 3307.89 \\
\hline \multirow{3}{*}{ Output and foreign price } & 0 & & 904.42 \\
\cline { 2 - 4 } & 1 & 3124.69 & 1025145.00 \\
\cline { 2 - 4 } & 2 & 837.08 & 942028.91 \\
\hline Output and foreign income & 0 & 3124.69 & \\
\cline { 2 - 4 } & 1 & 837.08 & \\
\cline { 2 - 4 } & 2 & & \\
\hline
\end{tabular}

The evidence adduced from the above table is overwhelmingly in favor of the value one for the relationships between foreign exchanges and output. This value clearly identifies the level at which the final prediction error reaches its minimum. Based on this result, it is pertinent to consider one lagged value for the test of the hypothesis that foreign exchanges lead to the growth rate of real output.

The interaction of contemporaneous and lagged values in the causality equation between foreign exchanges and output as well as the inclusion of both differentiated and level variables pose a potential problem; namely, the requirement of long term restrictions on vector autoregressive. In order to cope with the issue, Nwaobi (2004) formalizes a model that includes both contemporaneous and lagged values, and then excludes unnecessary coefficients so as to impose cointegration restrictions in the vector autoregressive. The causal relationship between foreign exchanges and output is thus reformulated as follows: $\alpha_{1}(\mathrm{~L}) \Delta \mathrm{Yr}_{t}=\alpha_{0}+\alpha(\mathrm{L}) \Delta \mathrm{V}_{t}+\mathrm{R}$

$\mathrm{R}$ stands for the residuals of the marginal model, $\alpha(\mathrm{L})$ is a polynomial of the form $\alpha(\mathrm{L})=\sum_{0}^{t} \varphi_{i} L^{i}$ in which $\mathrm{L}$ is polynomial in the lag operator such that $\mathrm{L}^{r} \mathrm{X}_{t}=\mathrm{X}_{t-r}$. From this development, a more general expression of the relationship between foreign exchanges and output is $(\Delta \mathrm{L}) \mathrm{Yr}_{t}=\alpha_{0}+\alpha_{1}(\Delta \mathrm{L}) \mathrm{Yr}_{t-1}+\alpha_{2}(\Delta \mathrm{L}) \mathrm{V}_{t}+\alpha_{3} \mathrm{R}$. 
The export led growth thesis, the inclusion of both differentiated and level variables, and the combination of lagged and contemporaneous values in the equation pertain to the assumptions that the causality relationship between foreign exchanges and output mainly consists of augmenting the output equation with the residuals of foreign exchanges as additional exogenous terms that are then tested for significance. Empirical analysis of the foreign exchange led growth necessitates the regression of the foreign exchange series to extract residuals and the estimation of these residuals in the output equation. In the first stage, open economy variables are regressed on the lags of the output operator determined by the final prediction error in order to extract the residuals; the second stage consists of testing the residual values in the output function. The table below confirms the existence of a causal relationship.

Table 3 - Residual Analysis

\begin{tabular}{|c|c|c|}
\hline Import & Foreign Price & Foreign Income \\
\hline 0.043 & -0.0965 & -0.031 \\
$(3.973)$ & $(-6.933)$ & $(-2.533)$ \\
{$[0.001]$} & {$[0.001]$} & {$[0.015]$} \\
\hline
\end{tabular}

(Values in parentheses are the t-statistics and values in brackets are probabilities)

The mean vector of foreign exchanges is quantified after each of the series imports, foreign price, and foreign income is regressed on the set of one real output lag. The significant response of the growth rate of output on the residuals of foreign exchanges shows evidence of a causal link running from imports, foreign price, and foreign income to output. The model exhibits evidence that foreign exchanges should be included in the growth model. This causality test clearly establishes that a high rate of foreign exchanges is positively associated with a higher rate of economic growth. Indeed, foreign exchange rationing leads to the growth rate of output and therefore prove that policies that spur imports, foreign price, and foreign income may be effective in raising the economic growth. Based on these results, it seems evident that the growth enhancing effect of open economy variables helps remove obstacles that prevent foreign exchanges not only from branching in the growth model, but also entering the supply side of the economy; hence, formally incorporated as cointegrated with money on the supply side of the economy.

\section{MACROECONOMIC POLICY IMPLICATIONS}

Application of the Barro-type analysis has been the cornerstone of the empirical examination of the money neutrality. However, the path to a uniform technique when applying the two-stage study is likely to be tumultuous due to a wide variety of estimating measures. This research extends the Barro-type reduced form output equation by according an important role to open economy variables. In an attempt to find a way the open variables should enter the model, foreign exchanges are modeled in conjunction with money supply. Following Nwaobi (2004), the model is developed from a structural form and adjusted to an open economy setting. Unlike existing models, foreign exchanges appear as cointegrated with money on the supply side of the economy.

\section{Economy Supply Function}

Estimation in the parameters of the model pertains to consider foreign exchanges and money in a cointegrated setting. An encompassing approach based on the extension of the policy variables through the inclusion of foreign exchanges in the supply side of the economy appears reasonable for dependent model of industrialized open economies. The empirical evaluation requires a statistical setting that departs from policy variables to arrive to a goal equation. According to Aziakpono (2003), anticipation of the policy variable is viewed as the lag operator on the parameter when individuals are able to form rational expectations. In this regard, anticipations of foreign price, foreign income, imports, and money series are expressed through the following equations:

$$
\begin{array}{ll}
\mathrm{E}_{t-1} \mathrm{M}_{t}=\beta_{1}(\mathrm{~L}) \mathrm{M}_{t-1} & \mathrm{E}_{t-1} \mathrm{I}_{t}=\beta_{2}(\mathrm{~L}) \mathrm{I}_{t-1} \\
\mathrm{E}_{t-1} \mathrm{E}_{t}=\beta_{1}(\mathrm{~L}) \mathrm{E}_{t-1} & \mathrm{E}_{t-1} \mathrm{~F}_{t}=\beta_{1}(\mathrm{~L}) \mathrm{F}_{t-1}
\end{array}
$$

Where $\mathrm{E}_{t-1} \mathrm{M}_{t}, \mathrm{E}_{t-1} \mathrm{I}_{t}, \mathrm{E}_{t-1} \mathrm{E}_{t}$, and $\mathrm{E}_{t-1} \mathrm{~F}_{t}$ represent the expectations formed on the basis of information available for the growth rate of money, imports, foreign price, and foreign income and tenotes an index of time. 
Policy variables are elaborated on the basis of the relationship between money, imports, foreign price, and foreign income series elaborated via the following functions:

$$
\begin{aligned}
& \mathrm{M}_{t}=\beta_{1}(\mathrm{~L}) \mathrm{M}_{t-1}+\mu_{t}^{1} \\
& \mathrm{E}_{t}=\beta_{3}(\mathrm{~L}) \mathrm{E}_{t-1}+\mu_{t}^{3}
\end{aligned}
$$

$$
\begin{aligned}
\mathrm{I}_{t} & =\beta_{2}(\mathrm{~L}) \mathrm{I}_{t-1}+\mu_{t}^{2} \\
\mathrm{~F}_{t} & =\beta_{4}(\mathrm{~L}) \mathrm{F}_{t-1}+\mu_{t}^{4}
\end{aligned}
$$

The policy variables M, I, E, and F represent the growth rate of money, imports, foreign price, and foreign income respectively. $\beta_{1}(\mathrm{~L}), \beta_{2}(\mathrm{~L}), \beta_{3}(\mathrm{~L})$, and $\beta_{4}(\mathrm{~L})$ denote lag operators in the above series and $\mu_{t}^{1}, \mu_{t}^{2}, \mu_{t}^{3}$, and $\mu_{t}^{4}$ are independently and identically distributed white noise random errors on these variables. Development of the policy variables helps determine the output function as follow:

$\mathrm{Y}_{t}=\beta_{1}(\mathrm{~L})\left(\mathrm{M}_{t}-\mathrm{E}_{t-1} \mathrm{M}_{t}\right)+\beta_{2}(\mathrm{~L})\left(\mathrm{I}_{t}-\mathrm{E}_{t-1} \mathrm{I}_{t}\right)+\beta_{3}(\mathrm{~L})\left(\mathrm{E}_{t}-\mathrm{E}_{t-1} \mathrm{E}_{t}\right)+\beta_{4}(\mathrm{~L})\left(\mathrm{F}_{t}-\mathrm{E}_{t-1} \mathrm{~F}_{t}\right)+\xi_{t}^{1}$

Where $\mathrm{Y}$ the goal variables, represent the growth rate of real output and $\xi_{t}^{1}$ is the white noise random errors independently and identically distributed. The unexpected movements of the money, imports, foreign price, and foreign income are given by the difference between the real and anticipated changes in these variables.

$$
\begin{array}{ll}
\mathrm{M}_{t}-\mathrm{E}_{t-1} \mathrm{M}_{t}=\mathrm{v}_{t}^{1} & \mathrm{I}_{t}-\mathrm{E}_{t-1} \mathrm{I}_{t}=\mathrm{v}_{t}^{2} \\
\mathrm{E}_{t}-\mathrm{E}_{t-1} \mathrm{E}_{t}=\mathrm{v}_{t}^{3} & \mathrm{~F}_{t}-\mathrm{E}_{t-1} \mathrm{~F}_{t}=\mathrm{v}_{t}^{4}
\end{array}
$$

Substitution of the unsystematic changes in money, imports, foreign price, and foreign income yields the real output

$\mathrm{Y}_{t}=\beta_{1}(\mathrm{~L})\left(\mathrm{v}_{t}^{1}\right)+\beta_{2}(\mathrm{~L})\left(\mathrm{v}_{t}^{2}\right)+\beta_{3}(\mathrm{~L})\left(\mathrm{v}_{t}^{3}\right)+\beta_{4}(\mathrm{~L})\left(\mathrm{v}_{t}^{4}\right)+\xi_{t}^{1}$

Where $\mathrm{v}_{t}^{1}, \mathrm{v}_{t}^{2}, \mathrm{v}_{t}^{3}$, and $\mathrm{v}_{t}^{4}$ are identically and independently distributed vectors of innovations for money, imports, foreign price, and foreign income series. The above equation supports the view that only innovations in the policy rule affect output. It seems evident that the major hypotheses to be tested are the effects of random changes in money, imports, foreign price, and foreign income on the growth rate of real output. The above formulation follows the Barro two-stage framework since the systematic components of the policy variables are excluded in the output equation and only the random parts are reflected in the growth model, leading to critic by Sheehey (1984) that the analysis is biased toward accepting the money neutrality hypothesis. Both random and nonrandom components of the policy variables are critical and inextricable part of the goal variable as suggested by the theoretical evidence and the preponderance of empirical reasoning because the bulk of economic literature consists of using both components of the policy variable in the goal equation to elaborate a model that reflects the economic reality.

\section{Unit Root Test}

The validity of the asymptotic distribution theory used to create a test statistic depends on the stationary of the data which helps determine the asymptotic statistical inference. Engle and Granger (1987) discover that many times series data possess a unit root, and therefore are not stationary. Testing the parameters depends on the stationary state of money and foreign exchange series because asymptotic statistical inference can only be made if these series are stationary. The presence of unit roots in times series leads to the problem of spurious regression which in turn, invalidates the application of standard ordinary least squares procedure and conventional statistical inference. Each series of the variable vector money, imports, foreign price, foreign exchange $X_{t}=[\mathrm{m}, \mathrm{i}, \mathrm{f}, \mathrm{e}]$ is tested for a unit root using the technique elaborated by Dickey and Fuller (1979) called the Augmented DickeyFuller (ADF) test. The choice of ADF is motivated by the fact that it accounts for higher order autoregressive process and ensures that the residuals are white noise. The ADF $(\rho)$ test for a series $Y$ is given by the t-statistic of $\varphi$ 
in the equation: $\Delta \mathrm{Y}_{t}=\varphi \mathrm{Y}_{t-1}+\sum_{i=1}^{\rho} \beta_{i} \Delta \mathrm{Y}_{t-1}+\xi_{t}$

Where $\xi_{t}$ is the vector of stochastic disturbance distributed independently and identically with mean zero and finite variance, and $\rho$ is the lag length. Statistical significance is conducted through the comparison of the t-statistic on $\varphi$ the coefficient of the series to critical values of MacKinnon elaborated using the Monte Carlo simulation technique. Investigation of the time series characteristics of money and foreign exchanges to ensure consistency with subsequent statistic modeling require data to be stationary because the computed t-statistic $\varphi /$ SE ( $\varphi$ ) does not follow a standard t-distribution in the vector autoregressive form. The series is stationary if Ho: $\varphi=0$ is rejected against the alternative of Ha: $\varphi<0$. Based on the form of regression and the sample size, the McKinnon critical values for rejection of the null hypothesis for a unit root are used for comparison of the test statistic of the $\varphi$ parameter.

Unit root test is carried out with only a constant since differencing of original variables eliminates the possibility of trend in the series. The choice of the lag length of one in is motivated by the result of the final prediction error. The commonly applied ADF test is thus used to compare of the t-statistic on the parameter with critical values constructed by McKinnon using a numerical simulation method. Results of the minimal number of times a series has to be first differentiated to until it becomes stationary are summarized below:

Table 4 - Unit root test

\begin{tabular}{|c|c|c|c|c|c|}
\hline \multirow[t]{2}{*}{ Variable } & \multicolumn{2}{|c|}{ Unit Root In Level } & \multirow[t]{2}{*}{ Variable } & \multicolumn{2}{|c|}{ Unit Root In First Difference } \\
\hline & T-Value & Lag Length & & T-Value & Lag Length \\
\hline $\mathrm{M}$ & -2.097494 & 1 & $\Delta \mathrm{M}$ & $-3.498310 * *$ & 1 \\
\hline $\mathrm{I}$ & -1.721221 & 1 & $\Delta \mathrm{I}$ & $-6.973204 *$ & 1 \\
\hline $\mathrm{E}$ & -1.522362 & 1 & $\Delta \mathrm{E}$ & $-5.009979 *$ & 1 \\
\hline $\mathrm{F}$ & -1.910217 & 1 & $\Delta \mathrm{F}$ & -1.659328 & 1 \\
\hline
\end{tabular}

Critical value in level

$99 \%$ critical value $=-3.571310$

Critical value in first difference

$95 \%$ critical value $=-2.922449$

$99 \%$ critical value $=-3.574446$

$95 \%$ critical value $=-2.922449$

$90 \%$ critical value $=-2.599224$

$90 \%$ critical value $=-2.599224$

$* *$ denotes significance at the $5 \%$ level
$*$ denotes significance at the $1 \%$ level

The result seems inconclusive with regard to the choice between stationary achieved by differencing of the series and stationary achieved by linear combination. The ADF test performed at the level of the variables provides strong evidence in favor of the null hypothesis of non-stationary for all the series of the variable vector $Z=[\mathrm{m}, \mathrm{i}, \mathrm{e}, \mathrm{f}]$. The test statistics in absolute values are lesser than the critical values at the conventional level of significance. However, all the variables appear to be stationary in first difference, except for the foreign income variable, when turning to the first difference of the series. The inclusion of the foreign income in first difference seems well suited with the model elaboration; it is supported by the economic reality that variations in the economic activities of developed countries affect the business cycle of the United States. The constraints imposed in the movement of money and foreign exchanges by the economic system in a long term horizon in the presence of short run digression from the estimated equilibrium are thus analyzed using stationary of the series achieved by differentiation of the original variables, therefore, all variables are treated as being stationary in first difference for the included series.

\section{Integration and Cointegration}

Cointegration test requires a setting of certain stochastic structure before empirical evaluation of time series data. The result provided by the final prediction error explains the use of a common lag length of one. Consideration is given to the possibility that the data generation process contains a constant and no deterministic time trend in the series. The inclusion of money and foreign exchanges through a vector autoregressive based cointegration technique that utilizes the methodology developed by Johansen (1988) helps set up the supply function. This procedure determines the rank prediction of the theoretical model and identifies the relationship between money, imports, foreign price, and foreign income. The vector autoregressive is of the form $Z_{t}=\Pi_{1} Z_{t-1}+\ldots+\Pi_{k} Z_{t-k}+\xi_{t}$ With $\mathrm{t}=1, . ., \mathrm{T}, \mathrm{Z}_{t}$ representing a sequence of random vectors of non-stationary variables, $\xi_{t}$ denoting a sequence of independently and identically distributed vectors of innovations, and $\Pi$ stands for a k x k co-integration matrix. 
Most economic variables are non stationary in level; therefore, the above equation is generally estimated in the first difference form as follow: $\Delta \mathrm{Z}_{t}=\Gamma_{1} \Delta \mathrm{Z}_{t-1}+\ldots .+\Gamma_{k-1} \Delta \mathrm{Z}_{t-k+1} \Pi \mathrm{Z}_{t-k}+\xi_{t}$. Cointegration equation is the existence of stationary achieved by linear combination among two or more non-stationary series; it represents the long run equilibrium relationship, in which variables linked by some theoretical relationship should not deviate from each other even though the presence of some deviation as a result of exogenous shocks ought to have the tendency to revert to the equilibrium relationship. Most studies associate the concept of cointegration with the statistical expression of the nature of such equilibrium. The (ADF) test is chosen among the alternative test to determine the order of integration of the series.

As stated in the Granger's representation if the long run matrix $\Pi$ has rank $\mathrm{r}<\mathrm{k}$, then there exist $\mathrm{kxr}$ matrices $\alpha$ and $\beta$ each with rank r such that $\Pi=\alpha \beta$. Each column of $\beta$ is interpreted as the $\mathrm{r}$ cointegration vectors and the matrix $\alpha$ forms the adjustments matrix, the coefficient matrix, or the matrix of error correction parameters. Johansen's strategy consists of the estimation of the $\Pi$ matrix from an unrestricted vector autoregressive and the test of whether the restriction implied by the reduced rank of $\Pi$ should be rejected or not. Two likelihood test statistics; namely, the trace test and the maximum eigenvalue test are used to find the number of cointegration relationship. The version of the first difference of the original variables is retained and used to allow for testing of the presence of cointegration relation between money, imports, foreign price and foreign income series whose summary is given in the table below:

Table 5 - Rank prediction of the theoretical model

\begin{tabular}{|c|c|c|c|c|c|c|}
\hline $\begin{array}{c}\text { Ho:Eigen } \\
\text { Values }\end{array}$ & $\begin{array}{c}\text { Ha: Eigen } \\
\text { Values }\end{array}$ & $\begin{array}{c}\text { Max Eigen } \\
\text { Values }\end{array}$ & $\begin{array}{c}\text { 95\% critical } \\
\text { values }\end{array}$ & Ha:Trace & $\begin{array}{c}\text { Trace } \\
\text { statistics }\end{array}$ & $\begin{array}{c}\mathbf{9 5 \%} \text { critical } \\
\text { values }\end{array}$ \\
\hline $\mathrm{R}=0$ & $\mathrm{R}=1$ & 29.33130 & 28.58 & $\mathrm{r}>=1$ & 57.16967 & 54.07 \\
\hline $\mathrm{R}<=1$ & $\mathrm{R}=2$ & 13.98298 & 22.29 & $\mathrm{r}>=2$ & 27.83837 & 35.19 \\
\hline $\mathrm{R}<=2$ & $\mathrm{R}=3$ & 8.391084 & 15.89 & $\mathrm{r}>=3$ & 13.85538 & 20.26 \\
\hline
\end{tabular}

From the above table, it can be observed that the outcome of the maximum eigen values test presents consistency with the trace statistic test results. Assuming a constant and no trend in the model, the maximum eigen value statistic does not reject $r=1$, while the trace statistic does not equally reject $r=1$. Both tests indicate one cointegration vector at the five percent level of significance. The analysis is consistent with the Fisher-Seater procedure that the appropriate form of the neutrality test is determined by the order of integration of the variables; therefore, the independent variables must be integrated of, at least one to conduct the neutrality test.

\section{Policy Equations}

Based on the lag length determined using the final prediction error, foreign exchange and money series are specified as a one order autoregressive distributed lag which contains errors correction terms (ECT) in order to capture the disequilibrium from the long run solution. Modeled jointly in a cointegration setting, the regression results of money, imports, foreign price, and foreign exchange prediction equations are given in the table below.

Table 6 - Short run analysis

\begin{tabular}{|c|c|c|c|c|}
\hline & $\Delta \mathbf{M}$ & $\Delta \mathrm{I}$ & $\Delta \mathbf{E}$ & $\Delta \mathbf{F}$ \\
\hline$\Delta \mathrm{M}_{-1}$ & $\begin{array}{c}0.24 \\
(2.03)\end{array}$ & $\begin{array}{c}1.48 \\
(2.72)\end{array}$ & $\begin{array}{c}0.09 \\
(0.17)\end{array}$ & $\begin{array}{c}-0.01 \\
(-0.23)\end{array}$ \\
\hline$\Delta \mathrm{I}_{-1}$ & $\begin{array}{c}-0.04 \\
(-1.04)\end{array}$ & $\begin{array}{c}0.12 \\
(0.65)\end{array}$ & $\begin{array}{c}0.07 \\
(0.41)\end{array}$ & $\begin{array}{c}0.05 \\
(3.55)\end{array}$ \\
\hline$\Delta \mathrm{E}_{-1}$ & $\begin{array}{c}0.01 \\
(0.04)\end{array}$ & $\begin{array}{c}-0.07 \\
(-0.46)\end{array}$ & $\begin{array}{c}0.30 \\
(2.00)\end{array}$ & $\begin{array}{c}-0.04 \\
(-3.05)\end{array}$ \\
\hline$\Delta \mathrm{F}_{-1}$ & $\begin{array}{c}0.06 \\
(0.34)\end{array}$ & $\begin{array}{c}0.12 \\
(0.16)\end{array}$ & $\begin{array}{c}0.61 \\
(0.86)\end{array}$ & $\begin{array}{c}0.81 \\
(14.20)\end{array}$ \\
\hline Constant & $\begin{array}{c}0.05 \\
(4.52)\end{array}$ & $\begin{array}{c}-0.02 \\
(-0.37)\end{array}$ & $\begin{array}{c}-0.02 \\
(-0.38)\end{array}$ & $\begin{array}{c}0.01 \\
(0.65)\end{array}$ \\
\hline ECT & $\begin{array}{c}-0.13 \\
(-4.01)\end{array}$ & $\begin{array}{c}0.15 \\
(1.01)\end{array}$ & $\begin{array}{c}0.08 \\
(0.54)\end{array}$ & $\begin{array}{c}-0.02 \\
(-1.52)\end{array}$ \\
\hline
\end{tabular}

(Values in parentheses are t-statistics) 
The above table infers that the supply side of the economic system is sensitive to imports, foreign price, foreign income, and money. The important aspect of the supply function resides in the statistically significant negative coefficient of the error correction term with respect to money. This is interpreted as the adjustment in one period for 13 percentage point when an exogenous shock disturbs the estimated equilibrium condition. This small adjustment of one period for the money shows evidence that a longer time period is needed for the money supply to revert to the estimated equilibrium in case of an economic shock.

\section{Goal Equation}

The hypothesis that unpredictable monetary policy affects output implies that the fitted values and the residuals values respectively the expected and unexpected components of the growth rate of the supply components of the economy enter the output equation. Following Barro (1978), the inclusion of lagged values is important in explaining output due to the assessment of the influence of potential deviations of exogenous variables. In this respect, the goal variable should be subject to time and lagged values of the random and nonrandom policy variables, in addition to the output variable taking into account its own lag. Based on the final prediction error test results, the goal variable uses one period lag of the output coefficient and one period lag of the expected and unexpected policy variables. The output functions used to analyze the anticipated and unanticipated components of the growth rate of money, imports, foreign price, and foreign income employs its own lag, and the contemporaneous and one lagged values of the policy variables in order to confer the greatest benefit in the exploration of the output coefficient in the determination of the goal equation.

Table 7 - Real output

\begin{tabular}{|c|c|c|c|c|c|c|c|c|c|}
\hline & $\mathrm{Y}_{t-i}$ & $\mathrm{AM}_{t-i}$ & $\mathrm{UM}_{t-i}$ & $\mathrm{AI}_{t-i}$ & $\mathrm{UI}_{t-i}$ & $\mathrm{AE}_{t-i}$ & $\mathrm{UE}_{t-i}$ & $\mathrm{AF}_{t-i}$ & $\mathrm{UF}_{t-i}$ \\
\hline $\mathrm{i}=0$ & & -0.02 & -0.01 & -0.02 & 0.01 & -0.03 & 0.01 & 1.03 & 0.97 \\
& & $(-0.53)$ & $(-0.98)$ & $(-1.04)$ & $(0.69)$ & $(-1.23)$ & $(1.36)$ & $(35.51)$ & $(25.51)$ \\
& & {$[0.60]$} & {$[0.33]$} & {$[0.31]$} & {$[0.49]$} & {$[0.23]$} & {$[0.18]$} & {$[0.00]$} & {$[0.00]$} \\
\hline $\mathrm{i}=1$ & -0.32 & 0.02 & 0.06 & 0.03 & 0.02 & 0.03 & 0.04 & 0.28 & 0.24 \\
& $(-1.56)$ & $(0.53)$ & $(0.99)$ & $(1.13)$ & $(1.01)$ & $(1.37)$ & $(1.26)$ & $(1.37)$ & $(1.20)$ \\
& {$[0.12]$} & {$[0.60]$} & {$[0.33]$} & {$[0.27]$} & {$[0.32]$} & {$[0.17]$} & {$[0.21]$} & {$[0.18]$} & {$[0.24]$} \\
\hline
\end{tabular}

(Values in parentheses are the t-statistics and values in brackets are probabilities)

The regression result reveals that only the expected and the unexpected components of the foreign income are significant at the conventional level of significance in a contemporaneous time frame. Indeed, any policy response of raising the level of output in the United States does not lead to offsetting expectations if the well-being of major business partners of the United States increase in a contemporaneous time-frame; independent on whether or not, the economic growth of the other industrialized countries is predicted. The evidence that short run cyclical movements in the output of highly industrialized countries tend to affect real output in the United States finds strong support in the model due to the significant nature of foreign income despite the lack of spread effects. A look at the variable that represents output of industrialized countries in the output equation indicates a significant trend rate of growth and the estimated value traces out a pattern of one percent a year.

Inconsistent with the financial logic is the lack of support of the apparent reality of output determination in industrialized economy models. Economic evidence that past realizations of growth tend to have a positive effect in the short run does not find support in this model. The magnitude of the lagged output coefficient is statistically insignificant. The impact of the real output observed in the previous period in estimating the current output is disappointing. The regressor predicts a negligible impact that the previous real domestic product exerts on current real domestic product in the economy. The silent nature of the money supply in both contemporaneous and delayed horizon refutes the theoretical argument of the influence of both random and nonrandom components of the money supply in the secular movements of output; therefore, an increase in the money supply has absolutely no effects on the level of growth. The foreign price variable reveals no depressionary or expansionary output effects of both prior and instantaneous values of the exchange rate. This result contradicts the viewpoint that the United States economy can quickly recover through a monetary policy aimed at depreciating the local currency; it also stands against the idea that devaluation tends to expand domestic output in highly industrialized countries. 


\section{CONCLUSION}

This article empirically unfastens the new classical structural model to include variables that operate through the supply side of the economy. The model adds open economy variables to the reduced form output equation for an in-depth exploration of the interaction between money and output. Previous studies on money neutrality have either included open economy variables in an ad-hoc fashion or ignored their influence in boosting the level of output. Indeed, the model is specialized to conform to industrialized economies with open markets. In a dynamic environment that manifests itself with the extraverted nature of the United States economy, results of macroeconomic policies could be rendered irrelevant without a major investigation on foreign exchange rationing. The presented analysis put forth foreign exchange variables that operate through the supply side of the economic system due to their importance to open economies models. Reformulation of the reduced form output equation is important in view of the apparent reality of industrialized countries with open markets. From the empirical standpoint, short run cyclical movements in the output of highly industrialized countries affect real output in the United States because the economic stimulus have the needed impact on output with a binding force to major business partners of the United States. The effect of the economic stabilization through devaluation of the dollar and the increase of money supply would not increase the level of real output. It is possible that measures aimed at increasing the real output should be directed to the level of growth of major United States business partners.

\section{AUTHOR INFORMATION}

Jean Emmanuel Fonkoua is a full-time faculty, Strayer University, USA. He has co-authored and published an article on the performance measure of CEO compensation. The study won the "best paper" of the session at a conference in Las Vegas organized by the Clute Institute i.e., certificate of best paper as well as automatic review for submission of publication. The article is currently published in the Journal of Business and Economic Research (JBER), Volume 2, February 2011. E-mail: fonkoua4@yahoo.com

\section{REFERENCES}

1. Attfield, C. L. F. \& Duck, N. W. (1983). The influence of unanticipated money growth on real output: Some cross-country estimates. Journal of Money, Credit and Banking, 15(4), 442-454.

2. Aziakpono, M. J. (2003). Money, output and price level in Nigeria: A test of the monetary neutrality proposition. UFS Working Paper, University of Bloemfontein, RSA.

3. Barro, R. J. (1978). Unanticipated money, output, and the price level in the United States. Journal of Political Economy, 86(4), 549-580.

4. Dickey D.A. \& Fuller, W.A. (1981). Likelihood ratio tests for autoregression time series with a unit root. Econometrica, 49, 1057-1072.

5. Edwards, S. (1983). The short-run relation between growth and inflation in Latin America: Comment. American Economic Review, 73(3), 477-482.

6. Engle, R.F. \& Granger C.W.J. (1987). Co integration and error correction: Representation, estimation and testing. Econometrica, 55(2), 251-276.

7. Fisher, M. E. \& Seater, J. J. (1993). Long Run Neutrality and Superneutrality in an ARIMA Framework, American Economic Review, 83, 402-415.

8. $\quad$ Greene, W. (2003). Econometric analysis ( $5^{\text {th }}$, Ed.). Prentice Hall.

9. Jafarey, S. \& Masters, A. (2003). Output, prices, and the velocity of money in search equilibrium. Journal of Money, Credit and Banking, 35(6), 871-888.

10. Jaleel, A. \& Kwan, A. (1991). Causality between exports and economic growth: Empirical evidence from Africa. Economic Letters, 37(3), 243-248.

11. Johansen, S. (1988). Statistical analysis of cointegration vectors. Journal of Economic Dynamics and Control, 12, 231-254.

12. Kwan, A. C. C. \& Kwok, B. (1995). Exogeneity and the export-led growth hypothesis: The case of China. Southern Economic Journal, 5(1), 1158-1166.

13. Nwaobi, G. C. (2002). A vector error correction and nonnested modeling of money demand function in Nigeria. Economic Bulletin, 3, 1-8. 
14. Nwaobi, G. C. (2004). Money and output interaction in Nigeria: An econometric investigation using multivariate cointegration technique. Economic Bulletin, 3(30), 1-10.

15. Romer, D. (2005). Advanced macroeconomic ( $3^{\text {rd }}$, Ed.). McGraw Hill.

16. Sheehey, E. J. (1984). The neutrality of the money in the short run: Some tests: Note. Journal of Money, Credit and Banking, 16(2), 237-241.

17. Wallace, F. \& Cabrera-Castellanos, L. (2006). Long run money neutrality: The case of Guatemala. Retrieved March 30, 2009, from: http://mpra.ub.uni-

muenchen.de/4025/MPRAPaperNo.4025,posted07.November2007/03:37 


\section{APPENDIX}

\section{A: Foreign Exchange Dataset}

\begin{tabular}{|c|c|c|c|c|c|c|c|c|c|c|}
\hline Obs & $\begin{array}{l}\text { Foreign } \\
\text { Income }\end{array}$ & $\begin{array}{c}\text { Foreign } \\
\text { Price }\end{array}$ & Imports & Output & I & $\mathbf{F}$ & $\mathbf{E}$ & $\mathbf{R E}$ & $\mathbf{R F}$ & $\mathbf{R I}$ \\
\hline 1960 & 0.2882 & 0.5303 & 22.432 & 0.2882 & 3.110489 & -1.244101 & -0.634312 & NA & NA & NA \\
\hline 1961 & 0.2912 & 0.5443 & 22.208 & 0.2912 & 3.100453 & -1.233745 & -0.608255 & -0.104014 & -0.027626 & -0.391105 \\
\hline 1962 & 0.2936 & 0.5583 & 24.352 & 0.2936 & 3.192614 & -1.225537 & -0.582859 & -0.083029 & -0.029663 & -0.328207 \\
\hline 1963 & 0.2963 & 0.5722 & 25.410 & 0.2963 & 3.235143 & -1.216383 & -0.558267 & -0.061933 & -0.028629 & -0.308872 \\
\hline 1964 & 0.2989 & 0.5862 & 27.319 & 0.2989 & 3.307582 & -1.207646 & -0.534094 & -0.041659 & -0.028948 & -0.262301 \\
\hline 1965 & 0.3027 & 0.6002 & 30.621 & 0.3027 & 3.421686 & -1.195013 & -0.510492 & -0.021778 & -0.024958 & -0.172886 \\
\hline 1966 & 0.3075 & 0.6141 & 35.987 & 0.3075 & 3.583158 & -1.179280 & -0.487597 & -0.004264 & -0.021722 & -0.047114 \\
\hline 1967 & 0.3149 & 0.6281 & 38.729 & 0.3149 & 3.656589 & -1.155500 & -0.465056 & 0.011577 & -0.013506 & -0.018142 \\
\hline 1968 & 0.3233 & 0.6421 & 45.293 & 0.3233 & 3.813152 & -1.129175 & -0.443011 & 0.023493 & -0.010706 & 0.071223 \\
\hline 1969 & 0.3345 & 0.6560 & 49.129 & 0.3345 & 3.894449 & -1.095118 & -0.421594 & 0.033697 & -0.002693 & 0.078128 \\
\hline 1970 & 0.3485 & 0.6700 & 54.386 & 0.3485 & 3.996107 & -1.054117 & -0.400478 & 0.040309 & 0.004618 & 0.083548 \\
\hline 1971 & 0.3620 & 0.6840 & 60.979 & 0.3620 & 4.110530 & -1.016111 & -0.379797 & 0.043526 & 0.002063 & 0.082107 \\
\hline 1972 & 0.3754 & 0.6979 & 72.665 & 0.3754 & 4.285860 & -0.979763 & -0.359679 & 0.047457 & 0.000812 & 0.150038 \\
\hline 1973 & 0.3885 & 0.7119 & 89.342 & 0.3885 & 4.492472 & -0.945462 & -0.339818 & 0.051838 & -0.000844 & 0.253936 \\
\hline 1974 & 0.4109 & 0.7259 & 125.190 & 0.4109 & 4.829833 & -0.889405 & -0.320343 & 0.056703 & 0.021279 & 0.494367 \\
\hline 1975 & 0.4455 & 0.7399 & 120.181 & 0.4455 & 4.788999 & -0.808558 & -0.301240 & 0.051931 & 0.046672 & 0.295125 \\
\hline 1976 & 0.4720 & 0.7538 & 148.798 & 0.4720 & 5.002590 & -0.750776 & -0.282628 & 0.036108 & 0.024473 & 0.280253 \\
\hline 1977 & 0.5015 & 0.7678 & 179.547 & 0.5015 & 5.190437 & -0.690152 & -0.264226 & 0.029901 & 0.027936 & 0.304817 \\
\hline 1978 & 0.5300 & 0.7261 & 208.191 & 0.5300 & 5.338456 & -0.634878 & -0.320068 & -0.051762 & 0.023236 & 0.281520 \\
\hline 1979 & 0.5664 & 0.7300 & 248.696 & 0.5664 & 5.516231 & -0.568455 & -0.314711 & -0.069947 & 0.034979 & 0.303101 \\
\hline 1980 & 0.6092 & 0.7185 & 291.241 & 0.6092 & 5.674151 & -0.495609 & -0.330590 & -0.114116 & 0.042114 & 0.273318 \\
\hline 1981 & 0.6612 & 0.8990 & 310.570 & 0.6612 & 5.738409 & -0.413699 & -0.106472 & 0.078975 & 0.051960 & 0.131723 \\
\hline 1982 & 0.7011 & 1.0224 & 299.391 & 0.7011 & 5.701750 & -0.355105 & 0.022153 & 0.172713 & 0.029523 & -0.136400 \\
\hline 1983 & 0.7286 & 1.1264 & 323.874 & 0.7286 & 5.780355 & -0.316630 & 0.119027 & 0.244631 & 0.010032 & -0.223375 \\
\hline 1984 & 0.7526 & 1.2717 & 400.166 & 0.7526 & 5.991879 & -0.284221 & 0.240355 & 0.349572 & 0.004379 & -0.120573 \\
\hline 1985 & 0.7745 & 1.3196 & 410.950 & 0.7745 & 6.018472 & -0.255538 & 0.277329 & 0.372743 & 0.001002 & -0.185564 \\
\hline 1986 & 0.7907 & 1.0194 & 448.572 & 0.7907 & 6.106069 & -0.234837 & 0.019214 & 0.102411 & -0.006673 & -0.179022 \\
\hline 1987 & 0.8093 & 0.8678 & 500.552 & 0.8093 & 6.215711 & -0.211586 & -0.141794 & -0.067414 & -0.003901 & -0.127878 \\
\hline 1988 & 0.8323 & 0.8470 & 545.715 & 0.8323 & 6.302097 & -0.183562 & -0.166055 & -0.101577 & 0.001121 & -0.107197 \\
\hline 1989 & 0.8616 & 0.9088 & 580.144 & 0.8616 & 6.363276 & -0.148964 & -0.095630 & -0.043088 & 0.007997 & -0.125207 \\
\hline 1990 & 0.8907 & 0.7870 & 616.097 & 0.8907 & 6.423404 & -0.115748 & -0.239527 & -0.201721 & 0.006986 & -0.162848 \\
\hline 1991 & 0.9212 & 0.8094 & 609.479 & 0.9212 & 6.412604 & -0.082078 & -0.211462 & -0.187803 & 0.007796 & -0.267513 \\
\hline 1992 & 0.9424 & 0.7739 & 656.094 & 0.9424 & 6.486304 & -0.059325 & -0.256313 & -0.246994 & -0.002760 & -0.288959 \\
\hline 1993 & 0.9620 & 0.8559 & 713.173 & 0.9620 & 6.569724 & -0.038741 & -0.155602 & -0.155974 & -0.004684 & -0.269834 \\
\hline 1994 & 0.9782 & 0.8445 & 801.747 & 0.9810 & 6.686793 & -0.022041 & -0.169011 & -0.178150 & -0.008348 & -0.210934 \\
\hline
\end{tabular}


The Journal of Applied Business Research-March/April 2013

Volume 29, Number 2

\begin{tabular}{|c|c|c|c|c|c|c|c|c|c|c|}
\hline 1995 & 1.0000 & 0.7732 & 890.771 & 1.0000 & 6.792087 & 0.000000 & -0.257218 & -0.274687 & -0.005655 & -0.160908 \\
\hline 1996 & 1.0177 & 0.7988 & 955.667 & 1.0177 & 6.862410 & 0.017545 & -0.224645 & -0.250285 & -0.007087 & -0.144794 \\
\hline 1997 & 1.0341 & 0.8859 & 1042.726 & 1.0341 & 6.949594 & 0.033531 & -0.121151 & -0.154264 & -0.008457 & -0.107190 \\
\hline 1998 & 1.0457 & 0.8921 & 1099.314 & 1.0457 & 7.002442 & 0.044687 & -0.114177 & -0.154099 & -0.013117 & -0.099517 \\
\hline 1999 & 1.0584 & 0.9400 & 1230.123 & 1.0584 & 7.114869 & 0.056758 & -0.061875 & -0.106548 & -0.012081 & -0.018612 \\
\hline 2000 & 1.0782 & 0.9232 & 1449.377 & 1.0782 & 7.278889 & 0.075293 & -0.079909 & -0.129724 & -0.005488 & 0.111295 \\
\hline 2001 & 1.1016 & 0.8952 & 1369.289 & 1.1016 & 7.222047 & 0.096764 & -0.110708 & -0.168416 & -0.002353 & 0.002076 \\
\hline 2002 & 1.1197 & 0.9454 & 1397.994 & 1.1197 & 7.242794 & 0.113061 & -0.056147 & -0.123000 & -0.007296 & -0.037850 \\
\hline 2003 & 1.1367 & 1.1321 & 1514.080 & 1.1367 & 7.322563 & 0.128129 & 0.124074 & 0.050280 & -0.008350 & -0.004133 \\
\hline 2004 & 1.1506 & 1.2438 & 1767.921 & 1.1506 & 7.477560 & 0.140284 & 0.218171 & 0.137959 & -0.011103 & 0.108281 \\
\hline 2005 & 1.1640 & 1.2449 & 1995.362 & 1.1640 & 7.598581 & 0.151862 & 0.219055 & 0.133666 & -0.011548 & 0.194956 \\
\hline 2006 & 1.1803 & 1.2563 & 2212.023 & 1.1803 & 7.701663 & 0.165769 & 0.228171 & 0.137851 & -0.009096 & 0.265318 \\
\hline 2007 & 1.1906 & 1.3711 & 2350.763 & 1.1986 & 7.762495 & 0.174457 & 0.315613 & 0.219370 & -0.014164 & 0.286854 \\
\hline 2008 & 1.2201 & 1.4726 & 2537.814 & 1.2201 & 7.839058 & 0.198933 & 0.387030 & 0.284233 & -0.004909 & 0.319940 \\
\hline 2009 & 1.2433 & 1.3935 & 1945.705 & 1.2433 & 7.573380 & 0.217769 & 0.331819 & 0.221450 & -0.003661 & 0.004021 \\
\hline 2010 & 1.2600 & 1.3261 & 2329.893 & 1.2651 & 7.753578 & 0.231112 & 0.282242 & 0.163851 & -0.008953 & 0.130990 \\
\hline
\end{tabular}




\section{B- Policy Dataset}

\begin{tabular}{|c|c|c|c|c|c|c|c|c|c|c|}
\hline Year & Money & $\mathbf{M}$ & UM & $\mathbf{A M}$ & UI & AI & $\mathbf{U E}$ & $\mathbf{A E}$ & UF & $\mathbf{A F}$ \\
\hline 1960 & 303.20 & 5.714393 & NA & NA & NA & NA & NA & NA & NA & NA \\
\hline 1961 & 324.95 & 5.783671 & NA & NA & NA & NA & NA & NA & NA & NA \\
\hline 1962 & 350.05 & 5.858076 & -0.001459 & 5.859535 & 0.016479 & 3.176135 & 0.027236 & -0.610095 & -0.001238 & -1.224299 \\
\hline 1963 & 379.75 & 5.939513 & 0.008144 & 5.931369 & -0.052201 & 3.287344 & 0.020607 & -0.578874 & -0.003776 & -1.212606 \\
\hline 1964 & 408.60 & 6.012737 & 0.002082 & 6.010655 & -0.033670 & 3.341253 & 0.019385 & -0.553479 & -0.001650 & -1.205996 \\
\hline 1965 & 441.50 & 6.090178 & 0.011162 & 6.079016 & 0.014822 & 3.406865 & 0.016941 & -0.527434 & 0.001172 & -1.196185 \\
\hline 1966 & 471.05 & 6.154964 & -0.003304 & 6.158269 & 0.052974 & 3.530184 & 0.012007 & -0.499604 & -0.001265 & -1.178016 \\
\hline 1967 & 504.15 & 6.222874 & -0.004439 & 6.227313 & -0.012137 & 3.668726 & 0.012867 & -0.477923 & 0.000568 & -1.156068 \\
\hline 1968 & 544.10 & 6.299133 & 0.001132 & 6.298001 & 0.073544 & 3.739608 & 0.012318 & -0.455329 & 0.001342 & -1.130517 \\
\hline 1969 & 579.00 & 6.361302 & -0.017448 & 6.378750 & -0.017974 & 3.912423 & 0.006912 & -0.428506 & 0.002135 & -1.097253 \\
\hline 1970 & 597.15 & 6.392168 & -0.047192 & 6.439361 & 0.029427 & 3.966680 & 0.007703 & -0.408181 & 0.006685 & -1.060802 \\
\hline 1971 & 676.30 & 6.516637 & 0.050571 & 6.466065 & 0.089730 & 4.020800 & 0.006680 & -0.386477 & -0.003783 & -1.012328 \\
\hline 1972 & 754.60 & 6.626188 & 0.020156 & 6.606032 & 0.003070 & 4.282790 & -0.004873 & -0.354807 & -0.001916 & -0.977847 \\
\hline 1973 & 834.90 & 6.727312 & 0.015911 & 6.711401 & 0.051682 & 4.440790 & -0.005739 & -0.334079 & -0.006139 & -0.939323 \\
\hline 1974 & 879.60 & 6.779467 & -0.036840 & 6.816307 & 0.199576 & 4.630257 & -0.002212 & -0.318131 & 0.014681 & -0.904087 \\
\hline 1975 & 969.05 & 6.876316 & -0.002546 & 6.878862 & -0.094548 & 4.883547 & -0.005753 & -0.295488 & 0.011381 & -0.819939 \\
\hline 1976 & 1071.95 & 6.977235 & -0.001483 & 6.978717 & 0.107711 & 4.894879 & -0.012559 & -0.270069 & -0.009006 & -0.741770 \\
\hline 1977 & 1222.25 & 7.108449 & 0.034814 & 7.073635 & 0.053712 & 5.136725 & -0.014101 & -0.250125 & -0.000976 & -0.689175 \\
\hline 1978 & 1321.30 & 7.186371 & -0.025336 & 7.211708 & -0.030339 & 5.368794 & -0.091889 & -0.228179 & -0.006810 & -0.628068 \\
\hline 1979 & 1428.90 & 7.264660 & -0.010795 & 7.275455 & 0.075777 & 5.440454 & 0.001169 & -0.315880 & 0.007712 & -0.576166 \\
\hline 1980 & 1537.35 & 7.337815 & -0.018375 & 7.356190 & 0.058141 & 5.616010 & -0.045836 & -0.284754 & 0.005511 & -0.501120 \\
\hline 1981 & 1676.10 & 7.424225 & -0.004622 & 7.428847 & -0.028339 & 5.766748 & 0.198284 & -0.304756 & 0.009592 & -0.423291 \\
\hline 1982 & 1829.85 & 7.511989 & -0.008901 & 7.520891 & -0.123794 & 5.825545 & 0.028978 & -0.006825 & -0.006972 & -0.348133 \\
\hline 1983 & 2061.45 & 7.631165 & 0.036038 & 7.595127 & -0.021187 & 5.801541 & 0.037956 & 0.081070 & -0.004538 & -0.312093 \\
\hline 1984 & 2221.60 & 7.705983 & -0.002889 & 7.708872 & 0.043448 & 5.948431 & 0.069371 & 0.170984 & -0.000125 & -0.284097 \\
\hline 1985 & 2423.60 & 7.793009 & 0.009857 & 7.783152 & -0.070938 & 6.089409 & -0.015079 & 0.292407 & -0.007239 & -0.248299 \\
\hline 1986 & 2618.90 & 7.870510 & -0.000155 & 7.870665 & -0.022645 & 6.128714 & -0.276032 & 0.295246 & -0.004602 & -0.230235 \\
\hline 1987 & 2780.45 & 7.930368 & 0.003415 & 7.926953 & -0.031913 & 6.247624 & -0.097110 & -0.044684 & -0.007786 & -0.203800 \\
\hline 1988 & 2947.70 & 7.988780 & 0.012742 & 7.976039 & -0.031376 & 6.333473 & 0.005575 & -0.171630 & -0.002028 & -0.181535 \\
\hline 1989 & 3045.75 & 8.021502 & -0.011912 & 8.033414 & -0.044560 & 6.407837 & 0.056694 & -0.152325 & 0.007194 & -0.156159 \\
\hline 1990 & 3224.05 & 8.078394 & 0.014794 & 8.063600 & 0.004132 & 6.419272 & -0.184913 & -0.054614 & 0.004755 & -0.120503 \\
\hline 1991 & 3359.15 & 8.119443 & 0.004775 & 8.114668 & -0.130931 & 6.543535 & 0.044119 & -0.255581 & $9.17 \mathrm{E}-05$ & -0.082170 \\
\hline 1992 & 3397.90 & 8.130913 & -0.014988 & 8.145901 & -0.012121 & 6.498425 & -0.079645 & -0.176668 & -0.000209 & -0.059117 \\
\hline 1993 & 3447.15 & 8.145303 & -0.002601 & 8.147904 & 0.029581 & 6.540143 & 0.092362 & -0.247964 & -0.001072 & -0.037669 \\
\hline 1994 & 3491.95 & 8.158216 & -0.014870 & 8.173085 & 0.080403 & 6.606390 & -0.059501 & -0.109509 & 0.000432 & -0.022473 \\
\hline 1995 & 3565.65 & 8.179102 & -0.014077 & 8.193178 & 0.069356 & 6.722731 & -0.094559 & -0.162659 & 0.001785 & -0.001785 \\
\hline 1996 & 3738.40 & 8.226413 & 0.006872 & 8.219541 & 0.020996 & 6.841414 & 0.047230 & -0.271875 & -0.009499 & 0.027044 \\
\hline 1997 & 3914.10 & 8.272341 & -0.003907 & 8.276248 & 0.014066 & 6.935528 & 0.085433 & -0.206585 & -0.001094 & 0.034625 \\
\hline 1998 & 4192.15 & 8.340969 & 0.012788 & 8.328181 & -0.006922 & 7.009363 & -0.028677 & -0.085500 & -0.003783 & 0.048469 \\
\hline
\end{tabular}


The Journal of Applied Business Research-March/April 2013

Volume 29, Number 2

\begin{tabular}{|c|c|c|c|c|c|c|c|c|c|c|}
\hline 1999 & 4516.55 & 8.415504 & 0.016204 & 8.399300 & 0.012029 & 7.102841 & 0.046828 & -0.108704 & $-6.19 \mathrm{E}-05$ & 0.056820 \\
\hline 2000 & 4772.70 & 8.470667 & -0.006163 & 8.476830 & 0.055319 & 7.223570 & -0.040273 & -0.039637 & 0.003887 & 0.071406 \\
\hline 2001 & 5188.40 & 8.554181 & 0.020356 & 8.533824 & -0.139490 & 7.361537 & -0.032959 & -0.077749 & -0.004894 & 0.101657 \\
\hline 2002 & 5569.90 & 8.625132 & 0.012953 & 8.612179 & -0.102818 & 7.345612 & 0.055543 & -0.111690 & 0.001256 & 0.111805 \\
\hline 2003 & 6020.35 & 8.702901 & 0.033078 & 8.669823 & -0.035249 & 7.357813 & 0.150466 & -0.026391 & 0.004193 & 0.123936 \\
\hline 2004 & 6270.80 & 8.743659 & -0.008719 & 8.752378 & 0.038318 & 7.439242 & 0.025474 & 0.192698 & 0.003329 & 0.136955 \\
\hline 2005 & 6510.10 & 8.781110 & -0.014877 & 8.795987 & 0.061461 & 7.537120 & -0.033461 & 0.252516 & -0.004194 & 0.156056 \\
\hline 2006 & 6852.20 & 8.832325 & -0.009366 & 8.841691 & 0.054516 & 7.647147 & 0.010266 & 0.217904 & -0.004159 & 0.169928 \\
\hline 2007 & 7288.00 & 8.893984 & -0.007184 & 8.901168 & -0.001175 & 7.763670 & 0.086960 & 0.228654 & -0.010416 & 0.184873 \\
\hline 2008 & 7774.40 & 8.958592 & -0.010360 & 8.968952 & 0.012802 & 7.826257 & 0.053635 & 0.333395 & 0.014499 & 0.184434 \\
\hline 2009 & 8454.45 & 9.042448 & 0.007234 & 9.035214 & -0.338054 & 7.911434 & -0.078736 & 0.410555 & -0.005379 & 0.223148 \\
\hline 2010 & 8609.20 & 9.060587 & -0.030268 & 9.090855 & 0.059310 & 7.694268 & -0.035096 & 0.317338 & 0.012408 & 0.218704 \\
\hline
\end{tabular}




\section{C: Output}

Dependent Variable: Y

Method: Least Squares

Date: 05/31/11 Time: 21:22

Sample (adjusted): 19632010

Included observations: 48 after adjustments

$\mathrm{Y}=\mathrm{C}(1) * \mathrm{Y}(-1)+\mathrm{C}(2) * \mathrm{AM}+\mathrm{C}(3) * \mathrm{UM}+\mathrm{C}(4) * \mathrm{AI}+\mathrm{C}(5) * \mathrm{UI}+\mathrm{C}(6) * \mathrm{AE}+\mathrm{C}(7) * \mathrm{UE}+\mathrm{C}(8)$

$* \mathrm{AF}+\mathrm{C}(9) * \mathrm{UF}+\mathrm{C}(10) * \mathrm{AM}(-1)+\mathrm{C}(11) * \mathrm{UM}(-1)+\mathrm{C}(12) * \mathrm{AI}(-1)+\mathrm{C}(13) * \mathrm{UI}(-1)$

$+\mathrm{C}(14) * \mathrm{AE}(-1)+\mathrm{C}(15) * \mathrm{UE}(-1)+\mathrm{C}(16) * \mathrm{AF}(-1)+\mathrm{C}(17) * \mathrm{UF}(-1)$

\begin{tabular}{|c|c|c|c|c|}
\hline & Coefficient & Std. Error & t-Statistic & Prob. \\
\hline $\mathbf{C}(\mathbf{1})$ & -0.317288 & 0.203393 & -1.559975 & 0.1289 \\
\hline $\mathrm{C}(2)$ & -0.021729 & 0.040698 & -0.533898 & 0.5972 \\
\hline $\mathrm{C}(3)$ & -0.010934 & 0.011161 & -0.979658 & 0.3348 \\
\hline $\mathrm{C}(4)$ & -0.023018 & 0.022071 & -1.042894 & 0.3051 \\
\hline $\mathbf{C}(5)$ & 0.001906 & 0.002757 & 0.691531 & 0.4944 \\
\hline $\mathrm{C}(6)$ & -0.031164 & 0.025425 & -1.225729 & 0.2295 \\
\hline $\mathrm{C}(7)$ & 0.003383 & 0.002479 & 1.364678 & 0.1822 \\
\hline $\mathrm{C}(\mathbf{8})$ & 1.030781 & 0.029025 & 35.51353 & 0.0000 \\
\hline $\mathbf{C}(9)$ & 0.972436 & 0.038121 & 25.50907 & 0.0000 \\
\hline $\mathrm{C}(10)$ & 0.019795 & 0.037275 & 0.531050 & 0.5992 \\
\hline $\mathrm{C}(11)$ & 0.055322 & 0.055822 & 0.991045 & 0.3293 \\
\hline $\mathrm{C}(12)$ & 0.025867 & 0.022941 & 1.127541 & 0.2682 \\
\hline $\mathrm{C}(13)$ & 0.021250 & 0.021006 & 1.011618 & 0.3196 \\
\hline $\mathrm{C}(14)$ & 0.034997 & 0.025475 & 1.373767 & 0.1794 \\
\hline $\mathrm{C}(15)$ & 0.042082 & 0.033391 & 1.260284 & 0.2170 \\
\hline $\mathrm{C}(16)$ & 0.280564 & 0.204094 & 1.374682 & 0.1791 \\
\hline $\mathrm{C}(17)$ & 0.241500 & 0.200777 & 1.202827 & 0.2381 \\
\hline R-squared & 0.999996 & & Mean dependent var & -0.372374 \\
\hline Adjusted R-squared & 0.999995 & & S.D. dependent var & 0.492188 \\
\hline S.E. of regression & 0.001139 & & Akaike info criterion & -10.44669 \\
\hline Sum squared resid & $4.02 \mathrm{E}-05$ & & Schwarz criterion & -9.783977 \\
\hline Log likelihood & 267.7206 & & Hannan-Quinn criter. & -10.19625 \\
\hline Durbin-Watson stat & 2.202388 & & & \\
\hline
\end{tabular}

